\title{
Seismic Moment Tensor Inversion Using 3D Velocity Model and Its Application to the 2013 Lushan Earthquake Sequence
}

\author{
Lupei Zhu ${ }^{\mathrm{a}, \mathrm{b}, *}$, Xiaofeng Zhou ${ }^{\mathrm{c}}$ \\ ${ }^{a}$ Subsurface Multi-scale Imaging Key Laboratory of Hubei Province, Institute of \\ Geophysics and Geomatics, China University of Geosciences, Wuhan, China \\ ${ }^{b}$ Department of Earth and Atmospheric Sciences, Saint Louis University, St. Louis, MO \\ 63108, USA \\ ${ }^{c}$ Institute of Geophysics, China Earthquake Administration Beijing, China
}

\begin{abstract}
Source inversion of small-magnitude events such as aftershocks or mine collapses requires use of relatively high frequency seismic waveforms which are strongly affected by small-scale heterogeneities in the crust. In this study, we developed a new inversion method called gCAP3D for determining general moment tensor of a seismic source using Green's functions of 3D models. It inherits the advantageous features of the "Cut-and-Paste" (CAP) method to break a full seismogram into the $P n l$ and surface-wave segments and to allow time shift between observed and predicted waveforms. It uses grid search for 5 source parameters (relative strengths of the isotropic and compensatedlinear-vector-dipole components and the strike, dip, and rake of the doublecouple component) that minimize the waveform misfit. The scalar moment is estimated using the ratio of $L_{2}$ norms of the data and synthetics. Focal
\end{abstract}

\footnotetext{
${ }^{*}$ Corresponding author; 3642 Lindell Blvd, St Louis, MO 63108, USA. Tel: +01-314977-3118

Email address: zhul@slu.edu (Xiaofeng Zhou)
}

Preprint submitted to Physics and Chemistry of the Earth

December 9, 2015

(C) 2016. This manuscript version is made available under the Elsevier user license http://www.elsevier.com/open-access/userlicense/1.0/ 
depth can also be determined by repeating the inversion at different depths. We applied gCAP3D to the $2013 M_{s} 7.0$ Lushan earthquake and its aftershocks using a 3D crustal-upper mantle velocity model derived from ambient noise tomography in the region. We first relocated the events using the double-difference method. We then used the finite-differences method and reciprocity principle to calculate Green's functions of the 3D model for 20 permanent broadband seismic stations within $200 \mathrm{~km}$ from the source region. We obtained moment tensors of the mainshock and 74 aftershocks ranging from $M_{w} 5.2$ to 3.4. The results show that the Lushan earthquake is a reverse faulting at a depth of $13-15 \mathrm{~km}$ on a plane dipping $40-47^{\circ}$ to $\mathrm{N} 46^{\circ} \mathrm{W}$. Most of the aftershocks occurred off the main rupture plane and have similar focal mechanisms to the mainshock's, except in the proximity of the mainshock where the aftershocks' focal mechanisms display some variations.

Keywords: Seismic moment tensor inversion, 3D Green's function, 2013 Lushan earthquake.

\section{Introduction}

An important task in seismology is to determine moment tensor of a seismic event using seismic observations. This $3 \times 3$ symmetric tensor with six independent components is defined as the integral of the "stress glut" over the source volume (e.g. Dahlen and Tromp, 1998). It provides fundamental information on the event magnitude, source geometry (e.g., possible fault plane orientations and slip directions), and partition among various deviatoric and isotropic components (e.g. Julian et al., 1998; Chapman and Leaney, 2012; Tape and Tape, 2012; Zhu and Ben-Zion, 2013; Vavrycuk, 
2015). Mathematically, the seismic moment tensor is linearly proportional to ground displacement and therefore can be obtained by a linear inversion of observed seismograms, assuming that the Earth structure and the location of the event are known accurately. In practice errors and uncertainties in velocity model and event location need to be taken into account. One critical condition for a reliable moment tensor solution by waveform inversion is that the arrival times of observed and predicted waveforms agree within a fraction of a cycle (Ekstrom et al., 2012). For this reason, most moment tensor inversions that use 1D Earth models for efficient forward calculation are done to low-pass-filtered seismograms. For example, the Global Centroid Moment Tensor (GCMT) project uses long-period (>40 s) body waves and surface waves. Theoretical seismograms are computed using normal modes of a 1D Earth model, with corrections to surface wave dispersion for lateral heterogeneity based on a tomographic whole-mantle model (Ekstrom et al., 2012). It works well for earthquakes larger than magnitude 5.5 globally. Hjorleifsdottir and Ekstrom (2010) assessed effects of 3D Earth structure on GCMT solutions using synthetic data and found only small errors on average in the scalar moment and tensor elements, though the centroid depths and times were biased. However, 3D effects become severe for moment tensor determination of moderate and small earthquakes for which higher frequency waveforms in regional distances are used for better signal-to-noise ratio (Kuhn and Vavrycuk, 2013). Covellone and Savage (2012) compared moment-tensor solutions of $195 M_{w}>5.5$ earthquakes in the Middle East between 1D and 3D inversions. At periods of 25-125 s, 3D inversion reduced error of the solutions. More importantly, using 3D velocity model increased 
the percentage of double-couple (DC) components, which suggests that the percentage of non-DC components was a result of poorly constrained Earth structure.

To reduce the dependence of seismic source inversion on velocity model and source location, Zhao and Helmberger (1994) developed a "Cut-andPaste" (CAP) method that breaks a regional seismogram into the Pnl and surface wave segments and allows time shift between observed and predicted waveforms. It uses a grid search of strike and dip of the fault plane and slip direction for the best focal mechanism that minimizes the misfit of observed and predicted seismograms, after the later is time shifted by crosscorrelating with the observed waveform. The focal depth is determined by repeating $\mathrm{CAP}$ at different source depths. Although $1 \mathrm{D}$ velocity models are used in CAP, it has been shown to be robust and reliable for earthquakes down to magnitude 3.5 using regional waveform data up to $0.5 \mathrm{~Hz}$ (e.g. Zhu and Helmberger, 1996; Zhu et al., 2006). Tan and Helmberger (2007) added a station-specified amplitude amplification factor (AAF) to CAP and extended earthquake magnitudes to 2 by inverting short-period $(0.5-2 \mathrm{~Hz}) P$ waveforms. The time shifting has also been adopted in several moment tensor inversion methods that use 1D (e.g. Dreger, 2003) or 3D velocity models (e.g. Ramos-Martinez and McMechan, 2001; Liu et al., 2004; Hingee et al., 2011).

There have been several improvements to CAP in addition to AAF. Zhu and Helmberger (1996) removed the normalization in the waveform misfit definition of original CAP using distance-decay-corrected true amplitudes in order to better preserve the information of source radiation pattern and $\mathrm{Pnl} /$ surface wave amplitude ratio which is critical for constraining the focal 
depth. Tan et al. (2006) added a grid search for epicenter to relocate earthquakes (CAPloc). Chen et al. (2015) used teleseismic waveforms in CAP (CAPtele) and combined teleseismic and regional seismograms (CAPjoint). Zhu and Ben-Zion (2013) proposed a new parameterization of seismic moment tensor and added grid search for the isotropic and compensated linear vector dipole (CLVD) components in a general moment tensor (gCAP). Despite these progresses, Green's functions of 1D velocity models are still used. CAP works fine in regions with moderate lateral structure variation because the time shifts absorb travel time anomalies of $P n l$ and surface waves. But $3 \mathrm{D}$ velocity models are desired for regions with strong lateral variation, such as at the boundaries of plates and tectonic blocks.

In this paper, we introduce a upgrade to CAP named gCAP3D that uses Green's functions of 3D velocity models to determine a seismic source's general moment tensor. Compared with other 3D velocity model moment tensor inversion methods that use whole seismograms and are thus dominated by the large-amplitude surface waves, gCAP3D inherits the unique feature of CAP of breaking the seismogram into the Pnl and surface wave segments. This allows to apply a higher band-pass filter and to increase the weight to the Pnl waveform which is more stable and less influenced by upper crustal heterogeneities than the surface waves (Zhao and Helmberger, 1994). The amplitude ratio of $P n l$ and surface wave provides better constrain on the source depth (Zhu and Helmberger, 1996; Zhu et al., 1997). We will apply gCAP3D to the 2013 Lushan $M_{s} 7.0$ earthquake in China and its aftershocks. The study area is located at the boundary between the Tibetan plateau and Sichuan Basin where crustal and upper mantle structure exhibits strong lat- 
Figure 1: Map showing the epicenter (the star) of the $2013 M_{s}$ 7.0 Lushan earthquake that occurred at the boundary between the Tibetan plateau and Sichuan Basin in China. Triangles are permanent broadband seismic stations within $200 \mathrm{~km}$ from the source region.

eral variation (Fig. 1) and thus provides an idea testing ground for gCAP3D.

\section{Method}

Let $u(t)$ be a segment of observed seismogram (e.g., Pnl, Rayleigh surface wave, or Love surface wave) with the instrument response removed and $s(t)$ be the corresponding synthetic seismogram that matches the observation with a time shift $\Delta t$ (due to imperfect velocity model or error in the source location),

$$
u(t)=M_{0} s(t-\Delta t), \quad t_{1} \leq t \leq t_{2},
$$

where $M_{0}$ is the scalar moment of the source. $s(t)$ is a linear combination of the Green's function $G_{i j}(t)$ from the source to the receiver,

$$
s(t)=D_{i j} G_{i j}(t) * S(t) .
$$

$S(t)$ is the source time function and $D_{i j}$ is the "normalized" moment tensor of the source (i.e., $\mathbf{D}: \mathbf{D}=2$ ). It can be decomposed into an isotropic (ISO) tensor, a DC tensor, and a CLVD tensor (Zhu and Ben-Zion, 2013),

$$
D_{i j}=\zeta D_{i j}^{\mathrm{ISO}}+\sqrt{1-\zeta^{2}}\left(\sqrt{1-\chi^{2}} D_{i j}^{\mathrm{DC}}+\chi D_{i j}^{\mathrm{CLVD}}\right)
$$


where

$$
\begin{aligned}
D_{i j}^{\mathrm{ISO}} & =\sqrt{\frac{2}{3}} \delta_{i j}, \\
D_{i j}^{\mathrm{DC}} & =n_{i} v_{j}+v_{i} n_{j}, \\
D_{i j}^{\mathrm{CLVD}} & =\frac{1}{\sqrt{3}}\left(2 b_{i} b_{j}-v_{i} v_{j}-n_{i} n_{j}\right),
\end{aligned}
$$

where $\hat{\mathrm{n}}$ is the fault normal vector (determined by the strike $\phi$ and $\operatorname{dip} \delta$ of the fault plane), $\hat{\mathrm{v}}$ is the slip direction vector (determined by the rake $\lambda$ ), and $\hat{b}=\hat{n} \times \hat{v}$ is the null vector. $\zeta$ and $\chi$ are non-dimensional parameters quantifying the strength of isotropic and CLVD components, respectively.

$$
\begin{aligned}
& |\zeta| \leq 1 \\
& |\chi| \leq 1 / 2 .
\end{aligned}
$$

CAP uses a grid search to solve Eq. (1) for DC source parameters $\phi, \delta$, and $\lambda$ (Zhao and Helmberger, 1994). For each possible set of DC source parameters, it first finds $\Delta t$ by cross-correlating $u(t)$ and $s(t)$ and estimates the scalar moment,

$$
M_{0}=\frac{\|u\|}{\|s\|},
$$

where \|\| denotes the $L_{2}$ norm. It then calculates the waveform misfit $e$ using the $L_{2}$ norm of the difference between observed and predicted waveform,

$$
e=\left\|u(t)-M_{0} s(t-\Delta t)\right\|^{2}
$$

The best DC source parameters are found that minimize $e$. The procedure is 
usually repeated at different source depths to find the optimal focal depth.

CAP uses 5 waveform segments from three-component seismogram of a station: the Pnl wave (vertical and radial components), the Rayleigh surface wave (vertical and radial components), and the Love surface wave (the transverse component). Stations at different epicentral distances $r_{i}$ are usually used. The total waveform misfit is the sum of misfits of all waveform segments used, after correcting for amplitude decay due to geometrical spreading (Zhu and Helmberger, 1996),

$$
\begin{aligned}
E & =\sum_{i=1}^{N_{s}}\left(w^{2}\left(\frac{r_{i}}{r_{0}}\right)^{2}\left(e_{i}^{\text {PnlZ }}+e_{i}^{\text {PnlR }}\right)\right. \\
& \left.+\frac{r_{i}}{r_{0}}\left(e_{i}^{\text {Rayl }}+e_{i}^{\text {RaylR }}+e_{i}^{\text {Love }}\right)\right)
\end{aligned}
$$

where $r_{0}$ is a reference distance and $w$ is the weight to the $P n l$ wave segment.

The uncertainties of source parameters

$$
\mathbf{m}=(\zeta, \chi, \phi, \delta, \lambda)^{\mathrm{T}}
$$

can be estimated using the "flatness" of the misfit $E$ at the minimum. We first estimate the posteriori data variance (Bevington and Robinson, 1992),

$$
\sigma_{d}^{2}=\frac{E_{\min }}{N_{d}-M}
$$

where $N_{d}$ is the total number of "data points" and $M$ is the number of unknown parameters (e.g., 6 for the moment tensor plus total number of time shifts). Since an individual sample on a seismogram strongly correlates 
with its neighbors, we count every duration of the dominant period as one independent data point. The covariance matrix of source parameters is

$$
C_{i j}=\sigma_{d}^{2}\left[\frac{\partial^{2} E}{\partial m_{i} \partial m_{j}}\right]^{-1}
$$

\section{Application to the 2013 Lushan earthquake and its aftershocks}

The 04/20/2013 $M_{s}$ 7.0 Lushan earthquake occurred in the southern part of the Longmenshan fault zone which marks the boundary between the highrise Tibetan plateau and low-land Sichuan Basin (Fig. 1). The collision between India and Tibet and the outward growth of the Tibetan plateau thrust the Longmenshan Mts. on top of the rigid Sichuan block. It is the largest earthquake in the fault zone following the $2008 M_{s} 8.0$ Wenchuan earthquake which ruptured $\sim 300 \mathrm{~km}$ of the Longmenshan fault. 196 deaths and more than 10,000 casualties were caused by the Lushan earthquake.

The area is part of the so-called "North-South Seismic Belt" in China and has been well instrumented by permanent seismic stations (Fig. 1). The Lushan earthquake and its aftershocks were recorded by more than 20 broadband three-component seismic stations within $200 \mathrm{~km}$ with excellent azimuthal coverage (Fig. 1). The DC moment tensors of the mainshock and large aftershocks were determined by using these regional waveform data and CAP (Lu et al., 2013; Zeng et al., 2013b). Xie et al. (2013) and Han et al. (2014) combined regional and teleseismic waveform data and used CAPtele as well as CAPjoint to determine the mainshock focal mechanism and depth. 1D velocity models were used in all these studies. Lin et al. (2013) obtained moment tensor of the mainshock and 16 aftershocks using time domain mo- 
Figure 2: Shear-wave velocity variation at different depths of the 3D crustal-upper mantle model used in this study.

ment tensor inversion TDMT_INV of Dreger (2003). They used three 1D models for stations located in different geologic provinces (i.e., plateau and basin).

Here we used a recent 3D crustal-upper mantle velocity model derived from dispersions of Rayleigh wave phase and group velocities and receiver functions (Zheng et al., 2013). The model extends down to $150 \mathrm{~km}$ depth and has a lateral resolution of 50-80 $\mathrm{km}$. S-wave velocity variations of the model at 5, 10, 20, and $50 \mathrm{~km}$ are shown in Fig. 2. Strong lateral velocity variation can be seen across the Longmenshan Fault Zone from the surface down to the lower crust and upper mantle.

We collected waveform data of the mainshock and 90 aftershocks in the following two weeks recorded by 20 broadband stations (Fig. 1), provided by Data Management Centre of China National Seismic Network at Institute of Geophysics, China Earthquake Administration (Zheng et al., 2010). We first relocated these events using their differential arrival times measured by waveform cross-correlation and the double-difference method (Waldhauser and Ellsworth, 2000). We then used a staggered-grid 4th-order finite-differences (FD) method (Graves, 1996) to calculate Green's functions of the 3D model. The $450 \mathrm{~km} \times 450 \mathrm{~km} \times 150 \mathrm{~km}$ crustal-upper mantle volume of the study area is divided into 1-km-spacing grid, which sets the maximum frequency of the Green's functions to be $0.4 \mathrm{~Hz}$. Since the number of source grids is more than the number of receivers, we used the reciprocity principle and initialized the FD source at the receiver. Only three FD runs were needed to obtain 18- 
component Green's functions for each station to all source grids (Zhao et al., 2006). For comparison, we also calculated 1D Green's functions of different epicentral distances and source depths using the FK method (Zhu and Rivera, 2002) and a 1D model of the study area developed by Zhao et al. (1997).

We band-pass filtered the $P n l$ waveforms between 0.03 and $0.3 \mathrm{~Hz}$ and surface waves between 0.02 and $0.1 \mathrm{~Hz}$. The two segments were given equal weights in the gCAP3D inversion. For the mainshock, we excluded close stations of epicentral distances less than $100 \mathrm{~km}$ so that the point-source approximation used in the inversion is valid. We tried triangle-shaped source time functions of different durations and found that a 4-s source duration yielded the minimum misfit. For all aftershocks, since the largest one is less than $M_{L} 5.5$ and waveforms were low-pass filtered at $3 \mathrm{~s}$ which is longer than the duration of the source, an impulse source time function was used. We also restricted that the moment tensors to DC only.

The moment tensor solutions of the mainshock using the $1 \mathrm{D}$ and $3 \mathrm{D}$ models are summarized in Table 1 along with other published results. Here we added the double-couple source constraint. Their waveform fits are shown in Fig. 3 and 4, respectively. Although the data variance reduction of $68 \%$ using the 3D model seems only slightly better than using the $1 \mathrm{D}$ model (64\%), the improvements to waveform fits are evident, particularly to the Rayleigh surface waves at all stations. The time shifts needed to align data and synthetics are also reduced (e.g., at stations JLO, DFU, MEK, etc). The ratio of waveform misfits between using the $3 \mathrm{D}$ model and $1 \mathrm{D}$ model is $F=1.12$. We used $F$-test and found that the decrease in misfit by the 3D 
Table 1: Moment tensor solutions of the Lushan mainshock using 1D and 3D velocity models with the double-couple constraint (1D and 3D) and using the 3D model with full moment tensor inversion (3Df).

\begin{tabular}{lllrllll}
\hline Name & $\phi$ & $\delta$ & $\lambda$ & $M_{w}$ & $h$ & $\zeta$ & $\chi$ \\
\hline 1D & $223 \pm 2$ & $37 \pm 4$ & $101 \pm 6$ & 6.4 & 15 & - & - \\
3D & $224 \pm 2$ & $41 \pm 4$ & $90 \pm 6$ & 6.5 & 13 & - & - \\
3Df & $222 \pm 2$ & $42 \pm 1$ & $90 \pm 2$ & 6.5 & 13 & $0.28 \pm 0.05$ & $-0.13 \pm 0.03$ \\
GCMT $^{\mathrm{a}}$ & 212 & 42 & 100 & 6.6 & 22 & - & 0.10 \\
CAP $^{b}$ & 210 & 47 & 97 & 6.7 & 12 & - & - \\
CAPjoint $^{c}$ & 210 & 44 & 91 & 6.7 & 16 & - & - \\
TDMT $^{\mathrm{d}}$ & 216 & 47 & 101 & 6.5 & 13 & - & 0.01 \\
\hline
\end{tabular}

$\phi, \delta$, and $\lambda$ are in degrees. $h$ is in $\mathrm{km}$.

a: www.globalcmt.org; b: Han et al. (2014); c: Xie et al. (2013); d: Lin et al. (2013).

model is significant at $92 \%$ confidence level.

We also did full moment-tensor inversion using the 3D velocity model (Table 1). Similar fault plane solutions were obtained but with appreciable isotropic $(\zeta=0.28)$ and CLVD $(\chi=-0.13)$ components, corresponding to $7.8 \%$ and $1.6 \%$ of total moment square, respectively. The variance reduction of $71 \%$ of full moment-tensor inversion is noticeably better than with the double-couple constraint (68\%). Given the deep depth of the earthquake (13-16 km), we believe that it is unlikely for the Lushan earthquake to have such amount of non-double couple components, especially the isotropic component. We found that most of the improvements to the waveform fits by the full-moment inversion are in the transverse components of seismograms. So it is possible that some of the anisotropic velocity structure not represented in the 3D isotropic model were mapped to isotropic and CLVD components of the source.

We used gCAP3D and determined moment tensors of 74 aftershocks (16 
Figure 3: Inversion result and waveform fits of the mainshock using the 1D velocity model. Stations are arranged by its epicentral distance (shown in $\mathrm{km}$ below the station name). Black traces are observed waveforms and red traces are predicted waveforms. The numbers below each waveform segment are time shift in s. and waveform cross-correlation coefficient in percentage.

Figure 4: Inversion result and waveform fits of the mainshock using the 3D velocity model, see caption of Fig. 3 for details.

Figure 5: Inversion result and waveform fits of a $M_{w} 3.4$ aftershock using the $3 \mathrm{D}$ velocity model, see caption of Fig. 3 for details.

aftershocks were discarded due to high noise level in their waveform records), ranging from $M_{w} 5.2$ to 3.4 . Fig. 5 shows waveform fits for the smallest aftershock. Excellent waveform match can be seen for 10-s Rayleigh surface waves at stations up to $\sim 120 \mathrm{~km}$, while the $P n l$ waveforms at $3 \mathrm{~s}$ and longer are noisy beyond $90 \mathrm{~km}$. Moment tensor solutions of these aftershocks are presented along with the mainshock in Fig. 6. Most of the aftershocks occurred off the main rupture plane and have focal mechanisms similar to the pure thrust faulting of mainshock's with one fault plane dipping about $40^{\circ}$ to the NW (Fig. 7). The strike of the plane $\left(224^{\circ}\right)$ agrees with the trend of the Longmenshan fault zone and the thrusting focal mechanisms are consistent with the horizontal shortening stress environment generated by the collision between the Tibetan plateau and Sichuan Block. There are a dozen of aftershocks in the proximity of the mainshock whose focal mechanisms display some variations, including one strike slip faulting and several reverse faulting on either high-angle or sub-horizontal plane. 
Figure 6: Focal mechanisms of the mainshock and 74 aftershocks obtained using the 3D velocity model. The bottom panel shows two SE-NW cross-sections perpendicular to the strike of the mainshock fault plane. The black line represents the projection of main rupture plane in the cross sections.

Figure 7: Stereographic project of $P$ and $T$ axes of focal mechanisms of 74 aftershocks. The $P$ and $T$ axes of the mainshock focal mechanism are indicated by the letters $P$ and $T$, respectively.

\section{Discussion and Conclusions}

When studying seismic sources of small magnitudes such as aftershocks or mine collapses it is necessary to apply moment-tensor inversions to waveforms of relatively high frequencies at which the signals are strong (e.g. Kuhn and Vavrycuk, 2013). Here we obtained moment tensor of 75 events of the 2013 Lushan earthquake sequence in the first two weeks following the mainshock. Using essentially the same dataset, Lin et al. (2013) determined moment tensors of 17 events by the TDMT_INV method and Lu et al. (2013) obtained moment tensors of 36 events by the CAP method. A critical parameter in these studies is the highest frequency of waveforms used: $0.05 \mathrm{~Hz}$ in Lin et al. (2013), 0.2 Hz in Lu et al. (2013), and $0.3 \mathrm{~Hz}$ in this study. At high frequencies seismic waves are strongly affected by small-scale heterogeneities in the crust, especially in the shallow part and block boundaries. With recent advancements in seismic tomography using travel-time and ambient noise data of dense arrays, high-resolution 3D Earth models will become available in various areas. A generalized moment tensor inversion using 3D Green's functions such as gCAP3D will find more applications to study seismic sources of tectonic, volcanic, and man-made events.

Overall, our moment tensor solution of the 2013 Lushan earthquake using 
3D Green's functions at regional distances is similar to those based regional and teleseismic waveforms (Tab. 1). The results show that it is a reverse faulting at a depth of $13-15 \mathrm{~km}$ on a plane dipping $40-47^{\circ}$ to $\mathrm{N} 46^{\circ} \mathrm{W}$. The $22 \mathrm{~km}$ centroid depth in GCMT is likely to be over-estimated, often found for events of this magnitude range in the GCMT catalog (Chu et al., 2009). The source duration of $4 \mathrm{~s}$ estimated in our study is noticeable shorter than the $10 \mathrm{~s}$ source duration based on finite source inversion using teleseismic body-wave waveforms (Zeng et al., 2013a; Liu et al., 2013). The discrepancy is probably due to the point-source approximation (Xie et al., 2013) and ignoring the rupture directivity effect. Future enhancements to gCAP3D includes adding a grid search for the rupture direction.

In summary, we have developed a new inversion method gCAP3D for determining general moment tensor of a seismic source using 3D Green's functions. It inherits the advantageous features of the "Cut-and-Paste" (CAP) method to break a full seismogram into the $P n l$ and surface-wave segments and to allow time shift between observed and predicted waveforms. It uses grid search for 5 source parameters (relative strengths of the isotropic and CLVD components and the strike, dip, and rake of the DC component) that minimize the waveform misfit. The scalar moment is estimated using the ratio of $L_{2}$ norms of the data and synthetics. We applied gCAP3D to the $2013 M_{s}$ 7.0 Lushan earthquake and its aftershocks using a 3D crustal-upper mantle velocity model derived from ambient noise tomography in the region. We first relocated the events using the double-difference method. We then used the finite-differences method and reciprocity principle to calculate Green's functions of the 3D model for 20 permanent broadband seismic sta- 
tions within $200 \mathrm{~km}$ from the source region. We obtained moment tensors of the mainshock and 74 aftershocks ranging from $M_{w} 5.2$ to 3.4. The re-

sults show that the Lushan earthquake is a reverse faulting at a depth of 13-15 km on a plane dipping $40-47^{\circ}$ to $\mathrm{N} 46^{\circ} \mathrm{W}$. Most of the aftershocks occurred off the main rupture plane and have similar focal mechanisms to the mainshock's, except in the proximity of the mainshock where the aftershocks' focal mechanisms display some variations.

\section{Acknowledgments}

We thank Vaclave Vavrycuk and an anonymous reviewer for their comments that helped us to improve the manuscript. Waveform data for this study are provided by Data Management Centre of China National Seismic Network at Institute of Geophysics, China Earthquake Administration. This study was supported by National Natural Science Foundation of China (41374060), China National Special Fund for Earthquake Scientific Research in Public Interest (201308011), and NSF grant EAS-1249701 of USA.

\section{References}

Bevington, P.R., Robinson, D.K., 1992. Data reduction and error analysis for the physical sciences. McGraw-Hill, Inc.

Chapman, C.H., Leaney, W.S., 2012. A new moment-tensor decomposition for seismic events in anisotopic media. Geophys. J. Int. 188, 343-370. doi:10.1111/j.1365-246X.2011.05265.x.

Chen, W., Ni, S., Kanamori, H., Wei, S., Jia, Z., Zhu, L., 2015. CAPjoint, a computer software package for joint inversion of moderate earthquake 
source parameters with local and teleseismic waveforms. Seismol. Res. Lett. 86, 432-441. doi:doi:10.1785/0220140167.

Chu, R., Zhu, L., Helmberger, D.V., 2009. Determination of earthquake focal depths and source time functions in central Asia using teleseismic $P$ waveforms. Geophys. Res. Lett. 36, L17317, doi:10.1029/2009GL039494.

Covellone, B.M., Savage, B., 2012. A quantitative comparison between 1D and 3D source inversion methodologies: Application to the Middle East. Bull. Seismol. Soc. Am. 102, 2189-2199.

Dahlen, F.A., Tromp, J., 1998. Theoretical Global Seismology. Princeton University Press, Princeton, NJ.

Dreger, D.S., 2003. TDMT_INV: Time domain seismic moment tensor inversion. International Handbook of Earthquake and Engineering Seismology 81B, 1627.

Ekstrom, G., Nettles, M., Dziewonski, A.M., 2012. The global CMT project 2004-2010: Centroid-moment tensor for 13,017 earthquakes. Phys. Earth Planet. Inter. 200-201, 1-9. doi:10.1016/j.pepi.2012.04.002.

Graves, R., 1996. Simulating seismic wave propagation in 3D elastic media using staggered-grid finite differences. Bull. Seismol. Soc. Am. 86, 10911106.

Han, L., Zeng, X., Jiang, C., Ni, S., Zhang, H., Long, F., 2014. Focal mechanisms of the 2013 Mw6.6 Lushan, China earthquake and high-resolution aftershock relocations. Seismol. Res. Lett. 85, 8-14. 
Hingee, M., Tkali, H., Fichtner, A., Sambridge, M., 2011. Seismic moment tensor inversion using a 3-D structural model: applications for the australian region. Geophys. J. Int. 184, 949-964. doi:10.1111/j.1365246X.2010.04897.x.

Hjorleifsdottir, V., Ekstrom, G., 2010. Effects of three-dimensional Earth structure on CMT earthquake parameters. Phys. Earth Planet. Inter. 179, $178-190$.

Julian, B.R., Miller, A.D., Foulger, G.R., 1998. Non-double-couple earthquakes: 1. theory. Rev. Geophys. 36, 525-549.

Kuhn, D., Vavrycuk, V., 2013. Determination of full moment tensors of microseismic events in a very heterogeneous mining environment. Tectonophysics 589, 33-43. doi:10.1016/j.tecto.2012.12.035.

Lin, X.D., Ge, H.K., Xu, P., Dreger, D., Su, J.R., Wang, B.S., Wu, M.J., 2013. Near-field full waveform inversion: Lushan magnitude 7.0 earthquake and its aftershock moment tensors (in Chinese with English abstract). Chinese J. Geophys. 56, 4037-4047. doi:10.6038/cjg20131209.

Liu, C., Zheng, Y., Ge, C., Xiong, X., Xu, H.Z., 2013. Rupture process of the 2013 M7.0 Lushan earthquake (in Chinese with English abstract). Science China: Earth Sciences doi:10.1007/s11430-013-4639-9.

Liu, Q., Polet, J., Komatisch, D., Tromp, J., 2004. Spectral-element moment tensor inversions for earthquakes in southern California. Bull. Seismol. Soc. Am. 94. doi:10.1785/012004038. 
Lu, J., Wang, X., Su, J., Pan, L., 2013. Hypocentral location and source mechanism of the $M_{s} 7.0$ Lushan earthquake sequence (in Chinese with English abstract). Chinese J. Geophys. 56, 1753-1763. doi:10.6038/cjg20130533.

Ramos-Martinez, J., McMechan, G.A., 2001. Source-parameter estimation by full waveform inversion in 3D heterogeneous, viscoelastic, anisotropic media. Bull. Seismol. Soc. Am. 91, 276-291.

Tan, Y., Helmberger, D., 2007. A new method for determining small earthquake source parameters using short-period P waves. Bull. Seismol. Soc. Am. 97, 1176-1195. doi:10.1785/0120060251.

Tan, Y., Zhu, L., Helmberger, D.V., Saikia, C.K., 2006. Locating and modeling regional earthquakes with two stations. J. Geophys. Res. 111, B01306, doi:10.1029/2005JB003775.

Tape, W., Tape, C., 2012. A geometric setting for moment tensors. Geophys. J. Int. 190, 476-498.

Vavrycuk, V., 2015. Moment tensor decompositions revisited. J. Seismol. 19, 231-252. doi:10.1007/s10950-014-9463-y.

Waldhauser, F., Ellsworth, W.L., 2000. A double-difference earthquake location algorithm: Method and application to the northern Hayward fault, California. Bull. Seismol. Soc. Am. 90, 1353-1368.

Xie, Z.J., Jin, B.K., Zheng, Y., Ge, C., Xiong, X., Xiong, C., Xu, H.Z., 2013. Source parameters inversion of the 2013 Lushan earthquake by combin- 
ing teleseismic waveforms and local seismograms (in Chinese with English abstract). Science China: Earth Sciences doi:10.1007/s11430-013-4640-38.

Zeng, X., Luo, Y., Han, L., 2013a. Preliminary result for rupture process of Apr. 20, 2013, Lushan Earthquake, Sichuan, China (in Chinese with English abstract). Chinese J. Geophys. 56, 1418-1424.

Zeng, X., Luo, Y., Han, L., 2013b. The Lushan M7.0 earthquake on 20 April 2013: A high-angle thrust event (in Chinese with English abstract). Chinese J. Geophys. 56, 1418-1424.

Zhao, L., Chen, P., Jordan, T.H., 2006. Strain Greens tensors, reciprocity and their applications to seismic source and structure studies. Bull. Seismol. Soc. Am. 96, 1753-1763.

Zhao, L.S., Helmberger, D.V., 1994. Source estimation from broadband regional seismograms. Bull. Seismol. Soc. Am. 84, 91-104.

Zhao, Z., Fan, J., Zheng, S.H., 1997. Precision determination of the crustal structure and hypocentral locations in the longmenshan thrust nappe belt (in Chinese with English abstract). Chinese J. Geophys. 19, 615-622.

Zheng, X.F., Yao, Z.X., Liang, J.H., Zheng, J., 2010. The role played and opportunities provided by IGP DMC of China National Seismic Network in Wenchuan earthquake disaster relief and researches. Bull. Seismol. Soc. Am. 100, 2866-2872. doi:10.1785/0120090257.

Zheng, Y., Ge, C., Xie, Z.J., Yang, Y.J., Xiong, X., Xu, H.Z., 2013. Crustal and upper mantle structure and the deep seismogenic environment in the 
source regions of the Lushan earthquake and the Wenchuan earthquake (in Chinese with English abstract). Science China: Earth Science 43. doi:10.1007/s11430-013-4641-2.

Zhu, L., Ben-Zion, Y., 2013. Parameterization of general seismic potency and moment tensors for source inversion of seismic waveform data. Geophys. J. Int. 194, 839-843. doi:10.1093/gji/ggt137.

Zhu, L., Helmberger, D.V., 1996. Advancement in source estimation techniques using broadband regional seismograms. Bull. Seismol. Soc. Am. 86, 1634-1641.

Zhu, L., Helmberger, D.V., Saikia, C.K., Woods, B.B., 1997. Regional waveform calibration in the Pamir-Hindu Kush region. J. Geophys. Res. 102, 22799-22813.

Zhu, L., Rivera, L.A., 2002. A note on the dynamic and static displacements from a point source in multi-layered media. Geophys. J. Int. 148, 619-627.

Zhu, L., Tan, Y., Helmberger, D.V., Saikia, C.K., 2006. Calibration of the Tibetan plateau using regional seismic waveforms. PAGEOPH 163, 11931213, doi:10.1007/s00024-006-0073-7. 


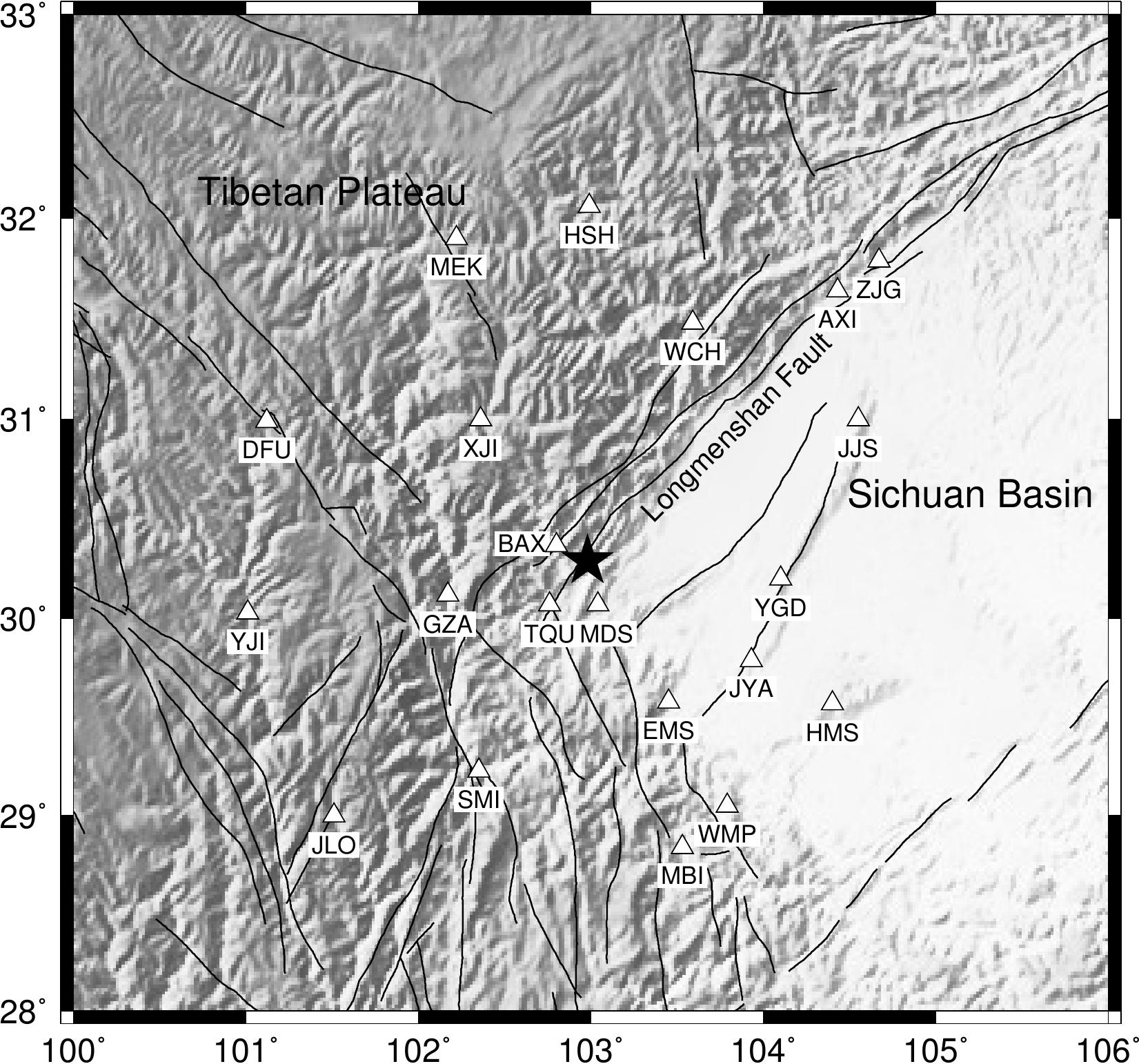




\section{Tibetan Plateau}

$32^{\circ}$

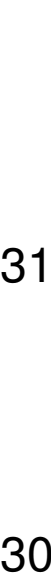

30

$29^{\circ}$

$28^{\circ}$

$100^{\circ}$
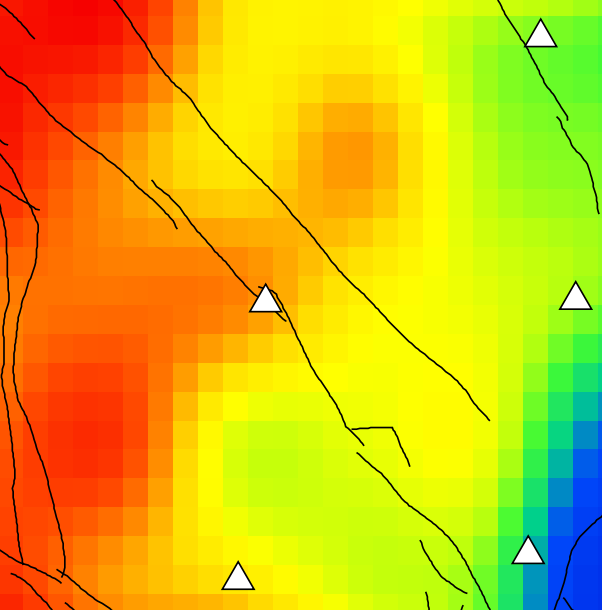

$\triangle$

28
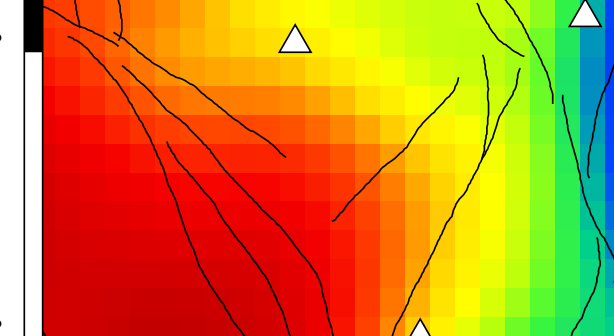

A
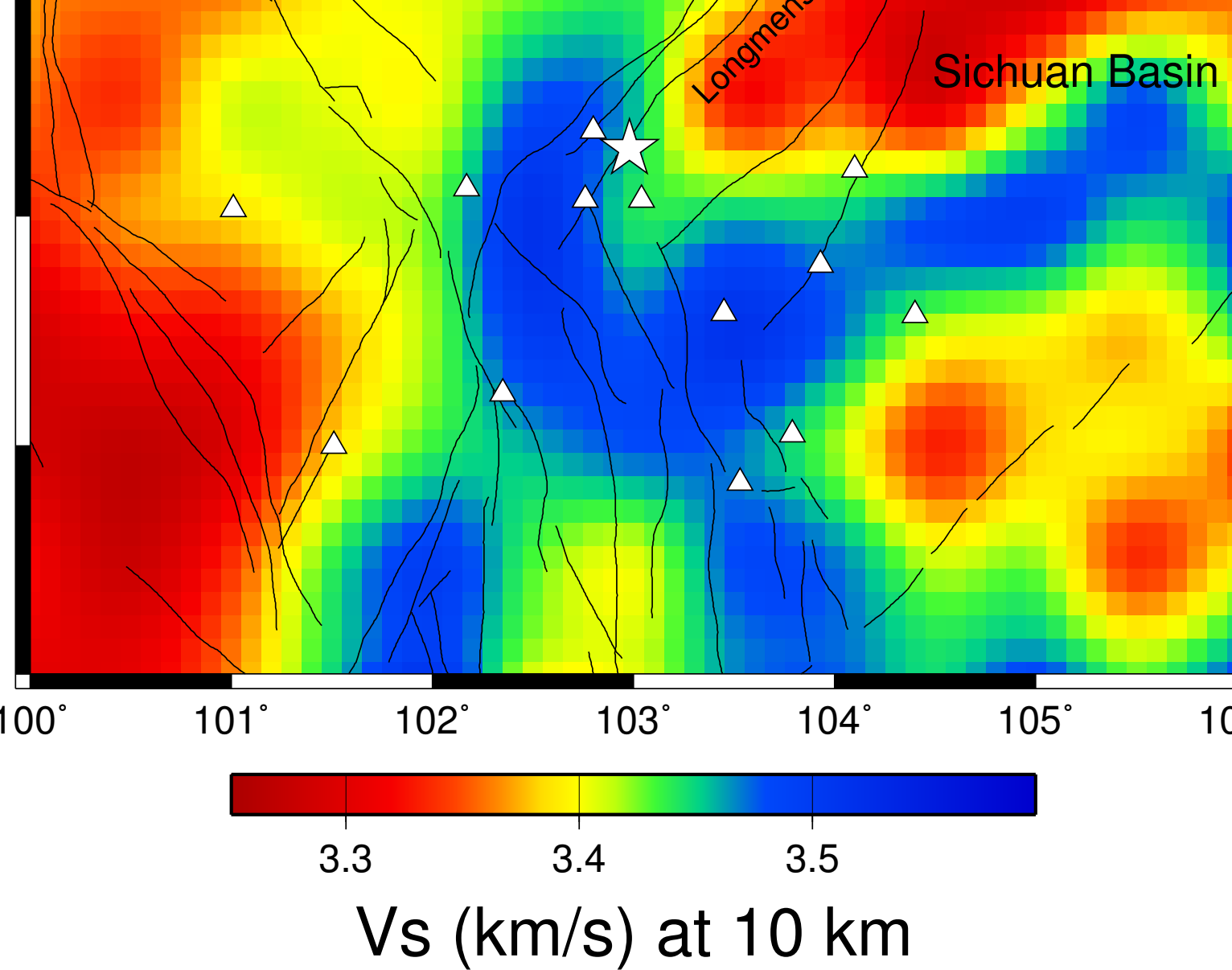


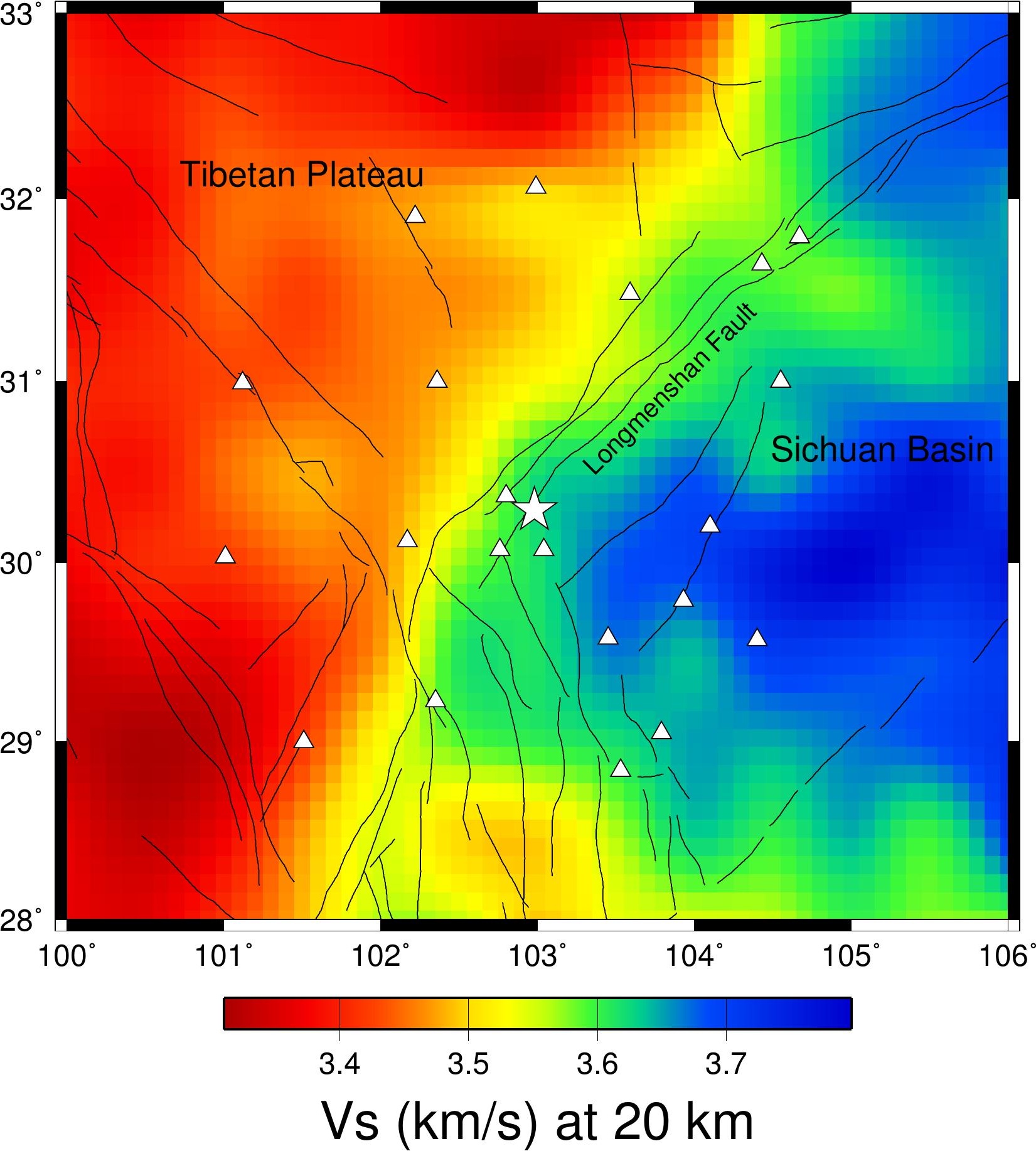




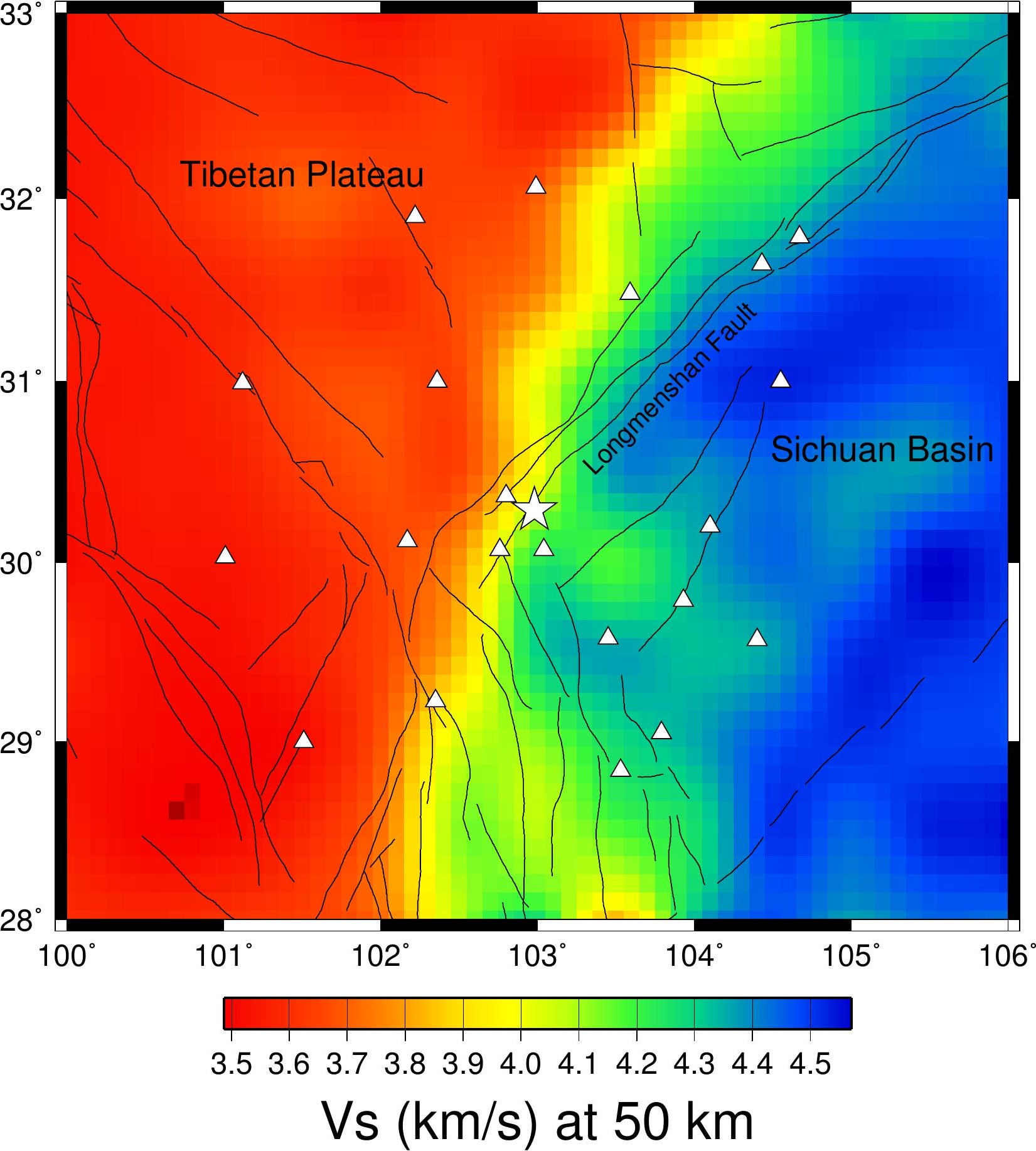


Event 20130420000246 Model and Depth 1D_15

FM 305482 Mw 6.37 E 8.109e+01589 ERR 246 ISO 0.000 .00 CLVD 0.000 .00 Variance reduction 64.0

\section{Pnlz Pnlr Raylz}

\section{SMI}

89

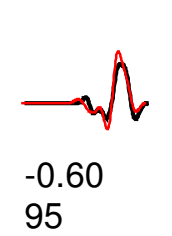

132.3/-0.06-w $-0.60$

Raylr

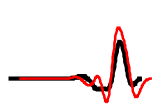

$2.10 \quad 1.40$

2.10

84

MMS

159.5/-0.91

$$
\begin{aligned}
& 0.60 \\
& 94
\end{aligned}
$$

MBI

169.9/0.01

$$
-0.40
$$

90

JJS

$170.4 / 0.49$

89

$-0.40$

89

0.60

95

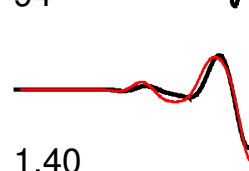

95

1.60

95

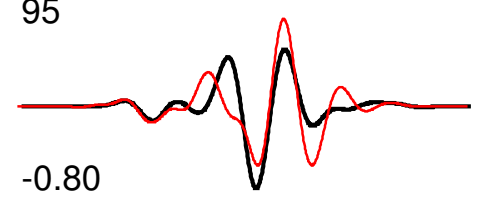

76

3.40

84

94

87

an

86

MEK

192.1/0.69

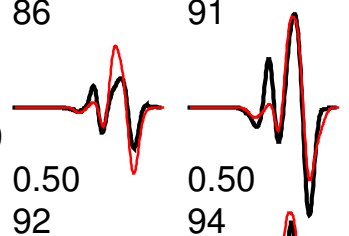

DFL

193

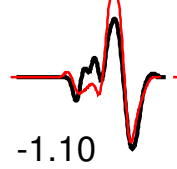

$91 \quad 73$

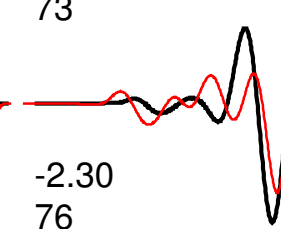

76
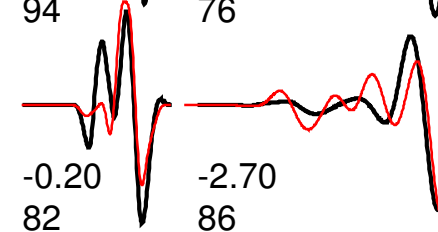

86 20

201.4/0.40

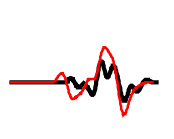

$-1.10$

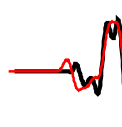

76
$-1.10$

90

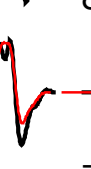

$-4.00$

70
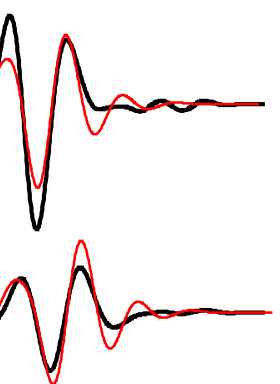

1.30

93

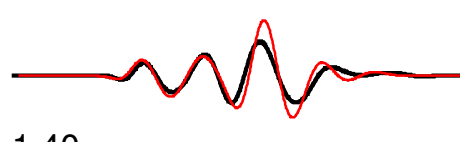

1.40

92

1.60

94

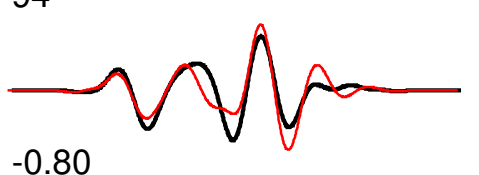

89
45
D. A N

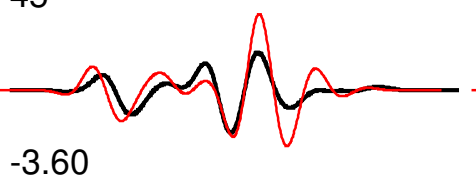

78

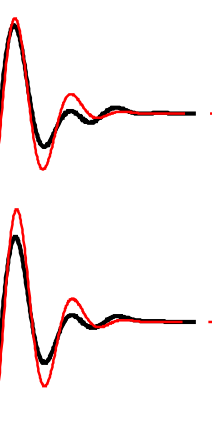

$-2.70$

88

79

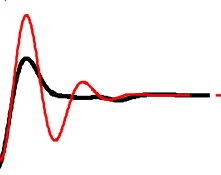

$-4.00$

69
Love

2.60

84

$-5.80$

35
0.60

16

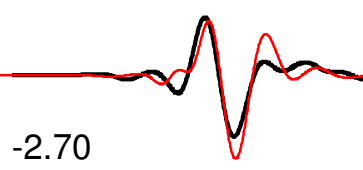

89
$-0.60$

96
$50 \mathrm{~s}$ 
Event 20130420000246 Model and Depth 3D_fix

FM 2244190 Mw 6.53 E 7.245e+01 590 ERR 246 ISO 0.000 .00 CLVD 0.000 .00 Variance reduction 68.3

\section{Pnlz Pnlr Raylz}

SMI

$132.3 / 0.86$

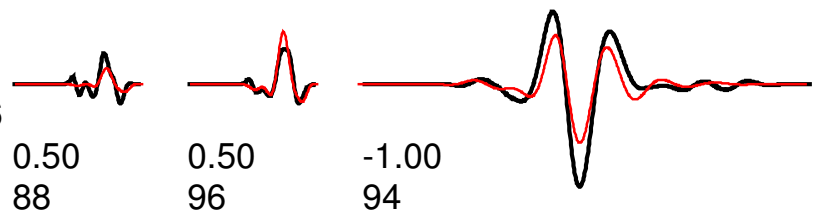

44.3/-1.01

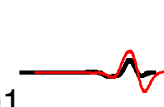

$$
3.00
$$

3.00

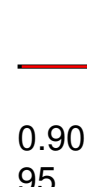

HMS

159.5/0.19

83

$\stackrel{N}{N}$

1.30

88

87

$\mathrm{MBI}$

$169.9 / 1.28$

$\mathrm{m}_{0.60}^{\mathrm{d}}$

95

98

JJS

$170.4 / 0.77$<smiles>CC1CCCCC1(C)C</smiles>

1.30

76

1.30
79

Nov

88

-1.50
97

84

$\prod_{0.40}^{N}$

94

$M$

2.00

73

$\sqrt{N}$

$2.00 \sqrt{-1.00}$

$85 \quad 90$

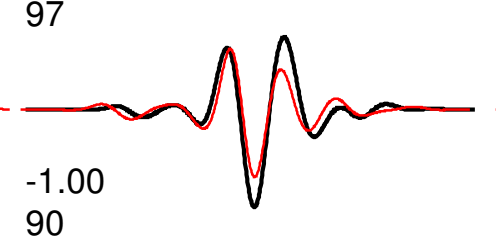

Raylr

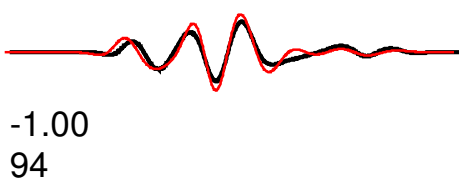

Love

1.20

87

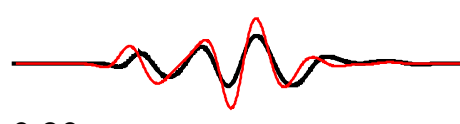

0.90

83

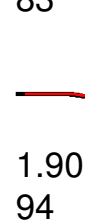

94

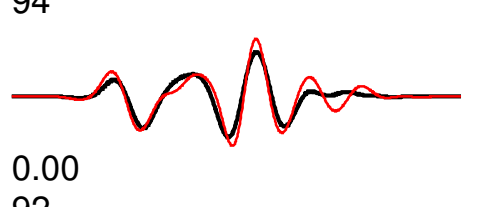

3.90

90

3.90
90

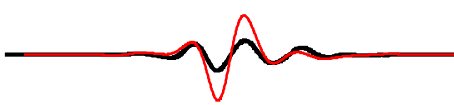

$-4.60$

36
ר

92
$-3.20$

2.30

63

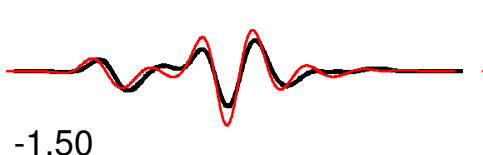

93

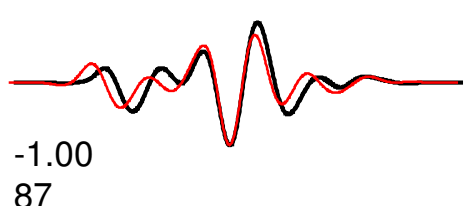

$-1.30$

96
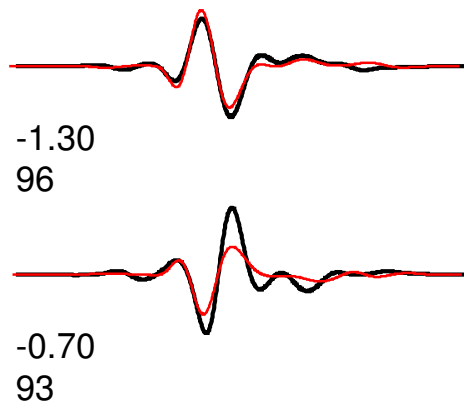

DFL

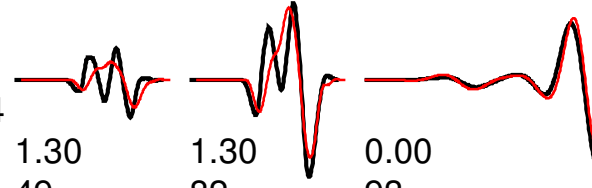

49

82

93

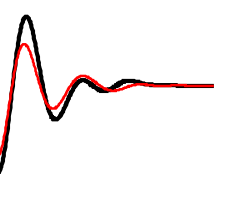

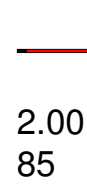

85

JLO 201.4/0.74
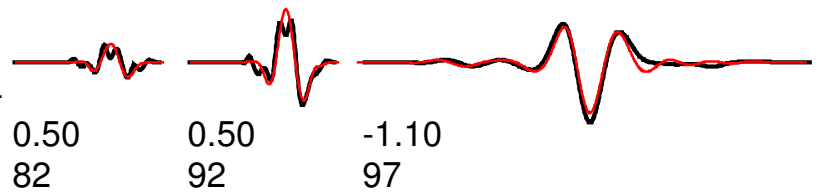

97

$-1.10$

$-1.30$

90

69 
Event 20130424133635 Model and Depth 3D_fix

FM 282772 Mw 3.36 E 4.584e-08 433 ERR 2410 ISO 0.000 .00 CLVD 0.000 .00 Variance reduction 84.1

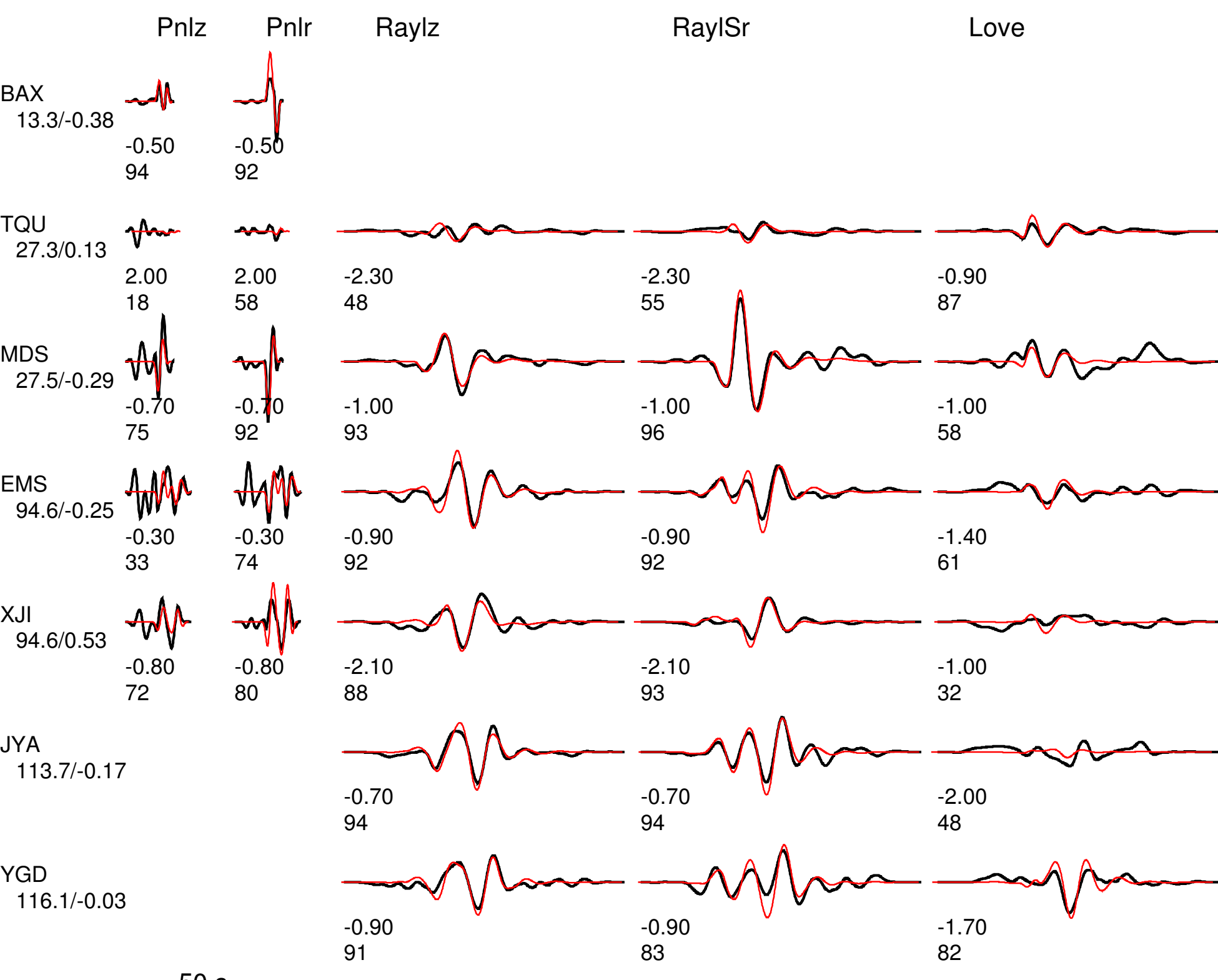




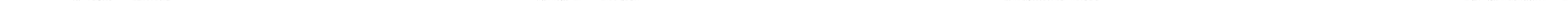




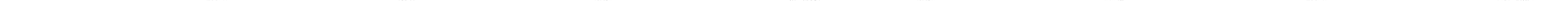


$0^{\circ}$

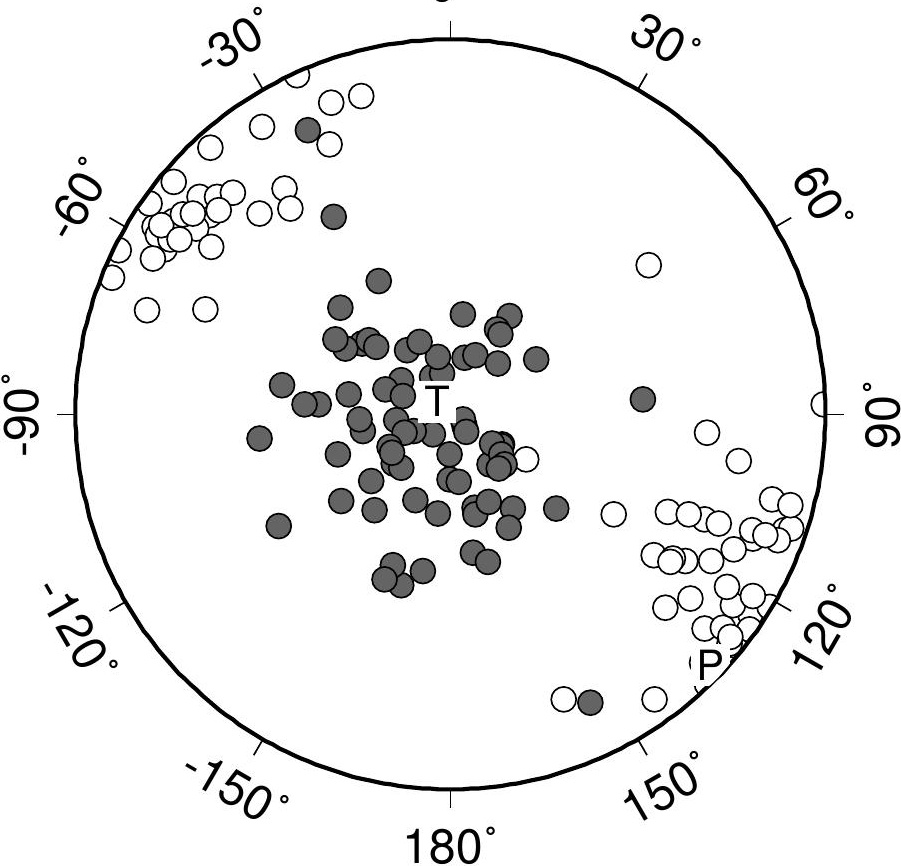

